\title{
Comparative Assessment of Health Systems in Russia and Finland
}

\author{
Molchanova E.V.* \\ Department of Modeling and Forecasting Regional Development, Institute of Economics, Karelian Research Centre, \\ Russian Academy of Sciences, Petrozavodsk, Russia \\ *Corresponding author.Email: molch@yandex.ru
}

\begin{abstract}
The state health system is the main mechanism within the organization medical and demographic policies, the preservation and strengthening of individual and public health of citizens. The purpose of this study is to compare the health systems in Russia and Finland through the methodology of the World Health Organization and the Global Burden of Disease. According to WHO recommendations, the evaluation of the efficiency of national health systems should be based on three basic principles: 1. preservation of individual and public health of the population, 2. ensuring commensurability of the burden of health care for all population groups, 3. respect for non-medical (ethical) aspects in the field of health care, respect for the honor and dignity of a patient. The methodology of the Global Burden of Disease project makes it possible to carry out the analysis of medical and demographic indicators characterizing the state of public health of a chosen state or a group of countries depending on a given period of time, sex, age, group and class of diseases, risk factors. The technique is based on the "disability-adjusted life years" index (DALY). The study made it possible to identify the advantages and disadvantages of the health systems in Russia and Finland. The assessment of the efficiency of the experience of introducing social innovations in Finland was made, directions of activity were proposed that can be applied in the development of programs in the field of medical and demographic policy in Russia. The results of the study can be used in various demographic documents, including in the field of high-tech medical care.
\end{abstract}

Keywords: health system, demography, health, social innovation, benchmarking, Russia, Finland.

\section{INTRODUCTION}

The state health system is the main mechanism in the organization of medical and demographic policies, the preservation and strengthening of individual and public health, and the reduction of morbidity and mortality. The dynamics of medical and demographic processes in the country depends on the efficiency of all parts of the system aimed at ensuring the health of citizens, on the correct choice of priorities and directions for the development of the sector of medical services. In order to develop an optimal model of health care in the Russian Federation, it is important to analyze the experience of developed foreign countries, which received worldwide recognition $[1,2]$.

Finland is currently one of these states. The country is characterized by high standard of living and quality of life, significant achievements in the field of health and demographic policy, including high life expectancy, low mortality rate, including infant mortality (Table 1). In 2018, 2019, 2020, Finland topped the ranking of the World Happiness Report compiled by the UN for the search for solutions to stable development based on 6 indicators characterizing various areas of socio-economic development.

The population density in Finland is not high, in terms of this indicator in Europe it is only ahead of Norway, Russia and Iceland. The country has a rather harsh climate, similar to the natural and climatic conditions characteristic of the territories of the North-Western Federal District of Russia. A significant share of the population is concentrated around the capitals, in our country Moscow, Moscow Region and the central regions of the European part, in Finland - Helsinki with the adjacent Greater Helsinki and Southern Finland. There are remote northern territories with very low population density both in our country and in the Republic of Finland. Thus, the highlighted common features make it especially interesting to compare the health systems between the two countries.

The purpose of this study is to compare the performance of health systems in Russia and Finland through the methodology of the World Health Organization (WHO) and the Global Burden of Disease (GBD) project. 
Table 1 Mortality and specific health indicators in Russia and Finland in 2017

\begin{tabular}{|l|c|c|}
\hline \multicolumn{1}{|c|}{ Indicator } & Russia & Finland \\
\hline Life expectancy at birth, both sexes & 72.7 & 81.7 \\
\hline Life expectancy at birth, men & 67.5 & 78.9 \\
\hline Life expectancy at birth, women & 77.6 & 84.5 \\
\hline Mortality per 100 thousand people & & \\
\hline All causes & 1243.6 & 975.9 \\
\hline Circulatory diseases & 587.6 & 360.2 \\
\hline Malignant neoplasms & 200.6 & 219.7 \\
\hline Infectious diseases & 23.9 & 4.6 \\
\hline External causes & 104.0 & 61.9 \\
\hline Infant mortality rate (per thousand live births) & 6.0 & 2.0 \\
\hline Maternal mortality rate (per thousand live births) & 7.3 & 3.0 \\
\hline
\end{tabular}

\section{METHODS AND MATERIALS}

According to WHO recommendations, the evaluation of the efficiency of national health systems should be based on three basic principles: 1 . preservation of individual and public health of the population, 2. ensuring commensurability of the burden of health care for all population groups, 3. respect for non-medical (ethical) aspects in the field of health care, respect for the honor and dignity of a patient. The methodology of the Global Burden of Disease project makes it possible to carry out the analysis of medical and demographic indicators characterizing the state of public health of a chosen state or a group of countries depending on a given period of time, sex, age, group and class of diseases, risk factors. The technique is based on the "disability-adjusted life years" index (DALY). The DALY=YLL+YLD index for various diseases or health disorders includes the years of lost life due to premature mortality (YLL - year life lost) and years of life lost as a result of health abnormalities (excluding fatalities, YLD - year lost due to disability). Time (lost years of healthy life) is used to measure the burden of disease when calculating the DALY index. The GBD project is coordinated by an independent research center in the field of global health - the Institute for Health Metrics and Evaluation (IHME), the information and analytical base of which is in the public domain and allows carrying out a variety of research work [3, 4]. This paper will be based on the synthesis of the WHO principles and information obtained from the information base of the GBD project.

\section{RESULTS}

The health system of Finland is the most decentralized among European countries and has proven to be effective over the years, which is reflected in such public health indicators as YLD, DALY (Table 2).

Table 2 Change of YLD, DALY (per 100 thousand people) from 1990 to 2017

\begin{tabular}{|c|c|c|c|c|}
\hline \multirow{2}{*}{ Year } & \multicolumn{2}{|c|}{ Russia } & \multicolumn{2}{c|}{ Finland } \\
\cline { 2 - 5 } & YLD & DALY & YLD & DALY \\
\hline 1990 & 12801 & 40433 & 13062 & 32915 \\
\hline 1995 & 12900 & 52047 & 13339 & 31269 \\
\hline 2000 & 13291 & 52134 & 13780 & 30845 \\
\hline 2005 & 13505 & 56530 & 14145 & 30370 \\
\hline 2010 & 13927 & 49879 & 14301 & 29819 \\
\hline 2015 & 14012 & 43355 & 14351 & 28555 \\
\hline 2017 & 13985 & 41884 & 14342 & 29091 \\
\hline
\end{tabular}

Since 1972, the Primary Health Care Act has assigned the primary responsibility for health and social services to municipalities (about three hundred of them nationwide) [5]. Municipal health centers provide both outpatient and 
inpatient qualified medical care, which does not require high-tech methods of treatment. Nevertheless, the advantage of these health centers is their good facilities with modern equipment, which allows conducting a variety of diagnostic studies. Medical health centers offer a wide range of services, from the treatment of acute exacerbation of chronic diseases to the primary and secondary prevention as needed. An important area of work is the activity of health schools to adapt patients with diabetes mellitus and who have suffered strokes and heart attacks. A separate priority area of municipal medical institutions is the protection of motherhood and childhood, preventive work with pregnant women and children under three years of age. The management of health centers is entrusted to chief doctors with higher medical education. The work of the centers is organized following the territorial principle, i.e. each district is assigned to general practitioners and nurses.

The second level of the health system uniting primary centers are hospital districts - federations of municipal district (20 such districts), each of them includes from 6 to 35 municipalities [6]. Hospital districts are grouped at an even higher level, into 5 units of special responsibility located around the university hospitals of Helsinki, Tampere, Oulu, Turku and Kuopio. The main activity of hospital districts is the provision of emergency care requiring surgery, as well as specialized treatment. Currently, the authority of special responsibility units in the field of interaction, planning and coordination of activities with hospital districts have been strengthened.

The health system in Finland is financed from several sources: state budget, compulsory insurance contributions, private funds, voluntary health insurance, including professional health insurance. The main share of expenses includes government subsidies, insurance contributions made to the Kela national insurance system (about 13-15\%), private funds amount to about $23-25 \%$. Paid services, including the purchase of expensive medicines, can be partially compensated through the Kela system. The main publicly accessible medical services in the Republic of Finland are financed by municipalities at the place of residence of patients. However, specialized assistance of narrow specialists (for example, an ophthalmologist, an ENT specialist, a surgeon) is partially paid for at its own expense, although the main burden of expenses is still borne by the state and municipalities.

Long-term specialized treatment is paid more from private funds. In Finland, $80 \%$ of medicines purchased from pharmacies are subject to reimbursement, i.e. partial or full reimbursement of their cost through compulsory health insurance. At the same time, the cost of drugs necessary for severe diseases is reimbursed in the amount of $100 \%$. In Finland, there are only two official suppliers of medicines, thus, the entire pharmacy network is attached to them. In hospitals, all medicines are purchased for budget money. In the field of drug supply, the main principle of prescribing therapy is the use of highly effective drugs, substantiated by evidence-based medicine. The prescription of a large number of drugs is not welcomed, the range of over-the-counter drugs is significantly limited.

Digital technologies in the field of health care have been greatly developed in Finland. In 2015, the country adopted a eSocial-2000 strategy aimed at improving the information base and increasing the quality and volume of online medical services provided by medical institutions. The national health information system KANTA, an analogue of the Russian Uniform State Health Information System (USHIS), was created in 2010. At present, absolutely all patient information is presented in electronic format, prescriptions are also digitized, prescribed procedures, diagnoses, waiting time for medical services are monitored [7]. The platform has several modules: for ordinary users of the system and the Terveysportti portal, where doctors can get the most up-to-date information and recommendations in the field of medical care. The information system is financed by medical institutions, any support for the portal by pharmaceutical companies is prohibited. All medical organizations, including private ones, are required to provide information to the national information system.

The largest amount of clinical data in encrypted form is contained in the hospital sector in the HILMO registry. It forms special electronic reports, which help to analyze the costs and efficiency of inpatient treatment using the principles of benchmarking [8]. Currently, an analogue of the KANTA system in the field of social protection (KANSA) is being launched, the final practical implementation of which is planned in 2023. In 2019, a unified system for measuring the quality of work of medical and social institutions KUVA was introduced helping administrative bodies to assess the efficiency of relevant institutions and adjust their health policy. It should be noted that the Finnish Ministry of Health exercises mild control and does not directly intervene in the activities of medical institutions. For tighter control, there are special supervisory units that evaluate the services provided in the field of health care, drug trafficking, etc.

Finland attaches great importance to the issue of health personnel. After the economic crisis of the nineties, the number of places for admission to medical educational institutions was doubled by 2016, some Finnish students study abroad and return to their homeland. Finland differs from other countries of the European Union in the relatively large proportion of average medical personnel, since there are more than four nurses per a doctor. At the same time, it should be noted that the training of nurses is quite demanding. The generally accepted norm was the expansion of the competence of nurses and their more active participation in the medical process, including consulting on issues that do not require special qualifications. Thus, in 2018, the number of appointments conducted by nurses at the level of outpatient care amounted to about $50 \%$.

The shortage of medical personnel in remote areas led to the need for greater universalization of general practitioners, allowing them to provide medical services in different classes of diseases. Most Finnish doctors work in 
the public health sector, about one fifth in the private sector. Private medicine in the Republic of Finland is extremely expensive, in certain cases the payment of medical services provided in the private sector, can be compensated by means of compulsory medical insurance in a small amount.

Similar to Russia the economic restrictions force the Finnish Government to take separate measures to optimize the health system. Thus, in 2018, 7 out of 15 central hospitals limited the range of medical services provided. The excessive autonomy of health centers also has negative effects, including the fragmentation of the health system and the heterogeneity of care depending on local capacities. The efforts are therefore being made to integrate small health centers into larger organizations. Finland's health care system is not static, various reforms are being undertaken and there is a great deal of emphasis on local initiatives. Globally, closer integration of health and social institutions is considered, within the framework of this vector new ideas (social innovations) are emerging at the regional level.

One of these innovations is the creation of multidisciplinary welfare centers, for example, Siunsote Health Centers in the province of North Karelia [6]. The center brings together doctors and nurses, various specialists, including in the field of narcology and mental health, as well as social workers. In the province of South Karelia, Eksote Houses for Children and Youth are being established, which provide diverse medical and social assistance, including in the field of mental health, maternal and child protection, psychological support, protection of the rights of children and youth. In one of the districts of Tampere, the Tesoma Center for Health and Well-Being was established. Tesoma is not one of the most prosperous areas in Tampere in social terms, so the Health Centre established there, which provides medical and social services and organizes joint leisure activities by the representatives of the local community, has become a successful example of a partnership between the state and the private sector.

The modern healthcare system of Russia has retained a centralized character inherited from the Soviet Union. The Soviet health system or the Semashko-Kaminsky system was formed according to one main principle - to provide accessible medical care to all citizens. Healthcare in the USSR was completely state. The Semashko-Kaminsky system showed its versatility and stability even in extreme situations, during the period of hostilities. It proved particular effectiveness in combating infectious diseases. However, the later period of the system revealed new problems: costs increased significantly, which were not accompanied by an adequate improvement in the quality of medical services, there was a technological lag behind developed countries, the efficiency of primary health care decreased, the gap between the quality of medical care at the level of local and central medical institutions increased [9].

During the transition from planned to market economy in the 1990s of the last century, the Russian health system experienced a number of serious shocks caused by underfunding and a significant reduction in the network of medical institutions. It was not possible to maintain government spending on the health care system during the transition to the market economy by the method of "shock therapy". In 1994, the health reform was carried out with the aim of moving to medicine with mixed sources of funding, such as compulsory insurance premiums, budget allocations, personal funds of citizens, donations, etc. Serious health problems and increasing negative trends in all indicators of public health forced the state in 1999 to change the vector of medico-demographic policy towards more planning in order to provide the minimum guarantees in the field of medical care for the population. Among other things, the use of state regulation methods in the production and sale of medicines was expanded. In 2011, the Russian Federation moved to the model closest to the Bismarck model of compulsory health insurance (CHI).

Despite the various stages of reform of the Russian health system, it remains a centralized three-level model with its roots deeply embedded in the Soviet health system. The model includes federal medical institutions, regional health organizations, municipal and rural organizations that provide medical care. It should be noted that there is a fairly extensive network of medical institutions in Russia. However, given the vast territories, low population density, there is still a problem of insufficient coverage of small and remote settlements by medical organizations, including the need for their staffing with qualified personnel and technological equipment.

Despite the emphasis of state policy on the insurance model of medicine, the lack of funding for state medical institutions, high bureaucratic burden on a doctor due to cumbersome reporting lead to the outflow of specialists, especially highly qualified doctors, to private medicine. The introduction of paid services in public health facilities is becoming increasingly common. The process of optimizing health care has greatly contributed to the displacement of narrow professionals from public to private health sector [10]. Initially, it was assumed that optimization would make health costs more rational by eliminating inefficient medical institutions and organizing well-equipped and staffed medical centers. The result was the weakening of the primary link of medical institutions closest to the population, the transition of specialists to the "paid sector" and migration from regions to large centers.

The passion for technological equipment of large federal and regional centers and the concentration of material investments at the upper levels of the health system also led to a significant weakening of the primary link. The backlog of small population centers in terms of doctors and medical personnel from large cities is one of the main problems of access to medical care in remote areas. In general, in the Russian Federation, the availability of doctors in rural areas is 3.5 times worse than the national average, and in the north-west of Russia this gap reaches 5.5 times [11].

Despite the long-standing stereotype of the leading role of the state in the healthcare sector of Russia, it is necessary to pay attention to the structure of current spending on healthcare. For example, in Finland, 
according to 2016 data, the share of private spending on health care in total amounted to $22.5 \%$, the share of budget inflows $-61.1 \%$, compulsory medical insurance funds $-13.3 \%$. In the Russian Federation, the situation is completely different, the share of private expenses since 2010 has grown by almost $5 \%$ and reached $43 \%$ in 2016, the share of budget expenditures amounted to $21.3 \%$ in the same year, the funds of compulsory medical insurance $-35.7 \%$ [12]. If we compare the structure of health spending in the Russian Federation with the leading European countries, it turns out that there is no such high share of private health spending in any developed European country. It should be noted that in the United States the share of private spending on health care is almost the same as in Russia, while the share of public spending on health care by GDP in this country is much higher than in developed European countries.

In the Russian Federation, the increase in private health spending is caused by the limited availability of many medical services financed by compulsory medical insurance and the outflow of specialists to the private practice. The possibility of providing paid services in public medical institutions also does not encourage them to reduce queues and improve the quality of medical services covered by CMI [13]. Comparing the insurance model of health care in the Russian Federation, it is possible to note its considerable difference from countries with the classic health care based on the principles of compulsory health insurance (for example, Germany, Japan, France). The share of CMI in the structure of health expenditures in these countries is significantly higher than in our country [14]. The efficiency of Russian insurance medical organizations designed to control the quality of medical services remains doubtful. To date, they function mainly as an intermediary financial link.

Comparing the financial resources of the health system of Russia and Finland it should be noted that the share of GDP spending on health care in Finland is almost twice as high as in the Russian Federation, and per capita spending is 3 times more. In analyzing the two health systems it should be noted that the Finnish health system, as already emphasized, is characterized by the reliance on a strong and independent primary link closest to the population, which manages a substantial share of public funds (at the level of 33-37\% of current health spending).

In the Republic of Finland, the role of secondary medical personnel is high compared to Russia, the provision of nurses and midwives per 10 thousand people is almost twice as high. Primary medical centers are well equipped with modern facilities. The unified information healthcare system was created much earlier than the Russian counterpart and has a wide coverage, both among patients and medical personnel. At the same time, there are common problems. Russian and Finnish health systems are characterized by a shortage of personnel on the periphery, a gap in the quality and accessibility of medical care in large centers and in remote areas.

The experience of Finland is also interesting because this country is by no means a world leader in health spending per capita, ranking only 15 among European countries. Nevertheless, Finland has achieved significant results in terms of medico-demographic indicators. One of the indicators for assessing the quality of the health system in the country is the opinion of citizens on the state of their health. According to the results of various surveys and studies, only $36 \%$ of Russians rate their health as "good", for the Finns this figure is $71 \%$.

\section{CONCLUSION}

Thus, Russia is characterized by its own characteristics, which shall be taken into account when planning the system of medical care, including the need to provide the minimum necessary medical care in the most remote areas, uneven density of population throughout the country, low availability of engineering and transport infrastructure in a number of settlements, personnel imbalances, insufficient technical equipment of medical institutions, and enormous deterioration of medical and demographic indicators in the 1990s.

To implement the main paradigm of the public health policy aimed at providing accessible and high-quality medical care to the entire population it is necessary to review the principles and amount of funding, with an increase in the primary level, close to patients; develop new CMI methods; ensure differentiated approach to staffing in large centers and in the periphery; foster the transition from the per capita principle of financing lowdensity territories to the principle of the necessary minimum security; universalize the health care in primary care facilities in small localities and rural areas; improve the quality of medical training; promote quality health services; provide advanced technical, transport and telecommunication services of remote territories; develop digital health care, including telemedicine technologies and integrated medical information systems, modern diagnostic methods; strengthen the health care logistics.

\section{ACKNOWLEDGMENT}

The study was carried out with the financial support of RFBR, project No. 18-010-00029_a "The possibility of introducing benchmarking in the development of medical and demographic policies".

\section{REFERENCES}

[1] E.V. Molchanova, Medical and demographic processes as a reflection of social and economic conditions of society in Russia, the Republic of Karelia and Finland, KarRC RAS, Petrozavodsk, 2012, 163 p.

[2] E.V. Molchanova, Medical and demographic situation in Russia, the Republic of Karelia and Finland, Population 1(55) (2012) 41-42. 
[3] C.J.L. Murray, A.D. Lopez, The Global Burden of Disease: a comprehensive assessment of mortality and disability from diseases, injuries, and risk factors in 1990 and projected to 2020, GBD Ser. Vol. I, Harvard University Press on behalf of the World Health Organization and The World Bank, Cambridge MA, 1996, $41 \mathrm{p}$.

[4] GBB 2016 Causes of Death Collaborators. Global, regional, and national age-sex specific mortality for 264 causes of death, 1980-2016: a systematic analysis for the Global Burden of Disease Study 2016, vol. 390, Lancet, London, 2017, pp. 1151-1210.

[5] One Hundred Social Innovations of Finland, under the red Ilkka Taipale, Finnish Literature Society, Helsinki, 2015, 364 p.

[6] Ilmo Keskimäki1, Timo Sinervo, Juha Koivisto, Integrating health and social services in Finland: regional and local initiatives to coordinate care, vol. 4, iss. 4, Public health panorama, WHO, December 2018, pp. 491-735.

[7] Katri Kilpeläinen, Suvi Parikka, Päivikki Koponen et al., Finnish experiences of health monitoring: local, regional, and national data sources for policy evaluation. Global Health Action, Taylor \& Francis Group, London, 2016, 9 p.

[8] U. Häkkinen, The Perfect project: measuring performance of health care episodes, Annals of Medicine 43(1) (2011) 1-3, London: Taylor \& Francis Group.
[9] L.D. Popovich, E.G. Potapchik., S.V. Shishkin, et al., Russian Federation. Health System Review. Health Systems: Time of Change, vol. 13, no. 7, World Health Organizat., Europ. Observatory for Health Syst. and Policies, Geneva, 2011, 251 p.

[10] E.V. Fadeeva, Optimization of health care and pension reform as a factor in the displacement of medical intelligentsia from the Public Health Sector, J. of the WGSU. Ser. Philos. Sociol. Art criticism 4 (2018) 107-117, Moscow: RGSU Publ. House.

[11] K.N. Kalashnikov, T.N. Likhachyova, Problem of shortage of medical personnel in rural areas, Issues of territorial development 2(37) (2017) 1-6.

[12] V.I. Perkhov, V.V. Lucko, Macroeconomic Expenditures on Health Care in Russia and Abroad, Modern Probl. of Health Care and Med. Statist. 2 (2019) 334-345, Univer. of the Higher School of Econ., Moscow.

[13] M.A. Gritsko, O.G. Polivaeva, Main trends as a result of commercialization of the social sphere (on the example of healthcare), Power and manag. in the East of Russ. 3(80) (2017) 54-62, Publ. House: Far Eastern Inst. of manag.-branch of the Russian Academy of national economy and public administration under the President of the Russian Federation, Khabarovsk.

[14] N.A. Avksentev, Forecast of health expenditure in Russia to 2030, Financial magazine 1(35) (2017) 63-76, Res. financial Inst. of the Ministry of Finance of the Russ. Fed., Moscow. 